\title{
Voltammetric Detection of Dopamine in Presence of Ascorbic Acid and Uric Acid at Poly (Xylenol Orange) Film-Coated Graphite Pencil Electrode
}

\author{
Umesh Chandra, B. E. Kumara Swamy, Ongera Gilbert, and B. S. Sherigara \\ Department of P. G. Studies and Research in Industrial Chemistry, Jnana Sahyadri, Kuvempu University, \\ Shankaraghatta-577 451, Shimoga, Karnataka (S), India \\ Correspondence should be addressed to B. E. Kumara Swamy, kumaraswamy21@yahoo.com
}

Received 17 February 2011; Accepted 6 April 2011

Academic Editor: Bengi Uslu

Copyright (C 2011 Umesh Chandra et al. This is an open access article distributed under the Creative Commons Attribution License, which permits unrestricted use, distribution, and reproduction in any medium, provided the original work is properly cited.

Poly (xylenol orange) film-coated graphite pencil electrode was fabricated for the detection of dopamine in the presence of ascorbic acid and uric acid in phosphate buffer solution of $\mathrm{pH}$ 7. The redox peaks obtained at modified electrode shows a good enhancement. The scan rate effect was found to be a diffusion-controlled electrode process. The electrochemical oxidation of dopamine was depended on $\mathrm{pH}$, and the limit of detection was found to be $9.1 \times 10^{-8} \mathrm{M}$. The simultaneous study gave and excellent result with great potential difference between dopamine and other bioactive organic molecules by using both cyclic voltammetric and differential pulse voltammetric techniques. The present modified graphite electrode was applied to the detection of dopamine in the injection samples, and the recovery obtained was satisfactory.

\section{Introduction}

The graphite pencil electrode (GPE) has been successfully acting as a biosensor in modern electroanalytical field. A porous composite is consisting of graphite particles, polymeric binder and other additives such as clay. Due to high electrochemical reactivity, high electrical conductivity, good mechanical rigidity, low cost, low technology, high electrochemical reactivity, ease of modification, renewal, low background current, and miniaturization, the GPE has good application in analysis of neurotransmitter and in the detection of traces of metal ions [1-4]. GPE has a larger active electrode surface area and is therefore able to detect low concentrations and/or volume of the analyt [5]. This type of electrode has been successfully applied to design various biosensors [6-9].

In recent days the electropolymer modified carbon paste electrode works with very much excellent effort in acting as a sensor for dopamine [10-12]. Especially, the electropolymer film-coated electrodes with dyes have good stability, reproducibility, more active sites, homogeneity in electrochemical deposition $[13,14]$. The electropolymerisation generally results in polymer film which is uniform and strongly adherent to the electrode surface. In addition the polymer film can be deposited onto the small area with high degree of geometrical conformity and controllable thickness. Several redox dyes are known to artificial electron donors [15]. Such dyes are able to undergo electropolymerisation from aqueous solution producing stable redox active layer $[16,17]$. Dopamine (DA) is a well-known biogenic amine acting as a neurotransmitter in the brain. It has received considerable attention because of its suspected role in a variety of neuropsychiatric disorders such as Parkinson's disease and Schizophrenia [18-21]. It has been found that the dopamine possesses very strong electrochemical activity by giving dopamine-o-quinone as oxidation product. However the determination remains a challenge because of the presence of large excess of ascorbic acid (AA) and uric acid (UA). It is generally believed that direct redox reactions of these species at bare electrode are irreversible and therefore requires high over potential [22]. Moreover the direct redox reactions of these species at bare electrodes take place at 


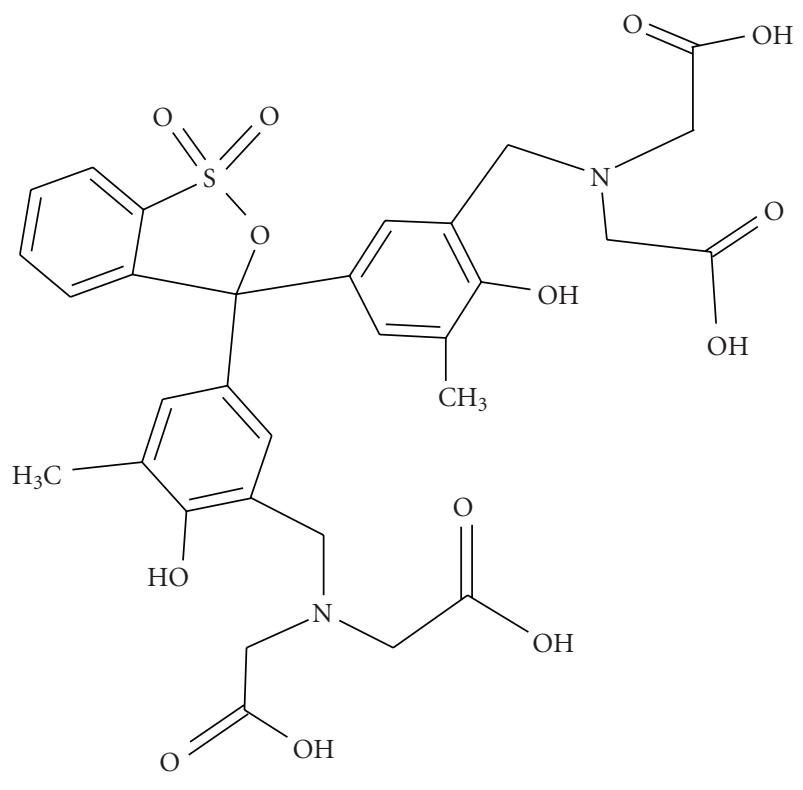

SCHEME 1: Structure of xylenol orange.

very similar potential and often suffer from a fouling effect, which results in rather poor selectivity and reproducibility. The ability to determine DA, UA, and AA selectively has been a major goal of electroanalytical research [23]. Development of both sensitivity and selectivity are of equal importance in voltammetric procedure and also this would help in the prevention and treatment of several neurodegenerative diseases [24].

The aim of our work was to fabricate stable electrode by electropolymerising xylenol orange (The structure of xylenol orange was shown in Scheme 1) on the surface of graphite pencil electrode to achieve the challenge of simultaneous determination of DA in the presence of AA, and UA in physiological $\mathrm{pH}$. In this investigation electrochemical method was chosen for the detection of DA because, the electrochemical methods have proved to be selective, sensitive, reliable, and cost effective [25]. Although no examination of the detection of dopamine in the presence of both ascorbic acid and uric acid in physiological $\mathrm{pH}$ at poly(xylenol orange) film-coated graphite pencil (poly(XO)/GPE) electrode has been reported. This work discussed about sensitivity, selectivity and reproducibility of neurotransmitter at poly (XO)/GPE at physiological $\mathrm{pH}$.

\section{Experimental}

2.1. Materials. The pencil-lead rods were (HB $0.5 \mathrm{~mm}$ in diameter and $6 \mathrm{~cm}$ length) purchased from local bookstore. $25 \times 10^{-3} \mathrm{M}$ xylenol orange stock solution was prepared in double-distilled water. $10 \times 10^{-5} \mathrm{M}$ DA stock solution was prepared in $0.1 \mathrm{M}$ perchloric acid solution. $10 \times 10^{-3} \mathrm{M}$ UA stock solution was prepared in $0.1 \mathrm{M} \mathrm{NaOH}$ and $10 \times 10^{-3} \mathrm{M}$ AA was prepared in double-distilled water. Buffer used was $0.2 \mathrm{M}$ phosphate buffer solution (PBS) and chemicals

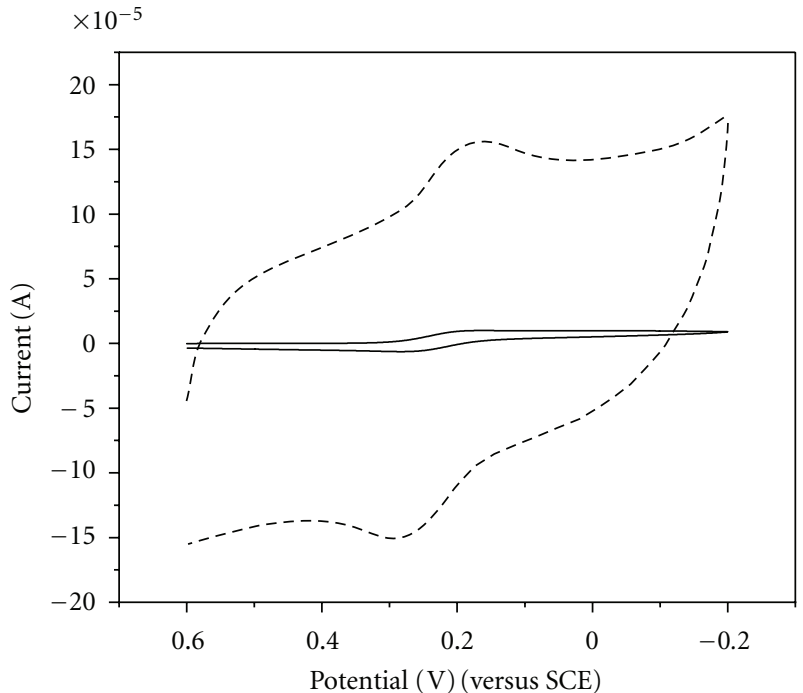

Figure 1: Cyclic voltammogram of $1 \mathrm{mM}$ potassium ferricyanide at BGPE (solid line) and at poly(XO)/GPE (dashed line) in $1 \mathrm{M}$ potassium chloride at scan rate of $50 \mathrm{mV} \mathrm{s}^{-1}$.

mentioned above were all analytical grade used without purification.

2.2. Apparatus. The electrochemical experiments were carried out using a model-201 electroanalyser (EA-201 chemilink system). The electrode system contained the working electrodes were bare graphite pencil electrode $(0.5 \mathrm{~mm}$ in diameter), platinum counter electrode and saturated calomel reference electrode.

2.3. Preparation of Poly $(X O) / G P E$. The $\operatorname{poly}(\mathrm{XO}) / \mathrm{GPE}$ was prepared by placing $5 \times 10^{-4} \mathrm{M}$ XO with $0.2 \mathrm{M}$ PBS at $\mathrm{pH}=10$ as supporting electrolyte in an electrochemical cell. The potential was maintained between $-400 \mathrm{mV}$ to $2000 \mathrm{mV}$ with 10 multiple cycles at scan rate of $100 \mathrm{mV} \mathrm{s}^{-1}$. The poly $(\mathrm{XO})$ film could be formed uniformly on the surface of GPE. After that, the electrode was rinsed with doubledistilled water and kept in the $0.2 \mathrm{M} \mathrm{PBS}$ at $\mathrm{pH} 7$.

\section{Results and Discussion}

3.1. Electrochemical Characterization of Poly(XO)/GPE Using Standard Potassium Ferricyanide System. The freshly prepared $1 \times 10^{-3} \mathrm{M}$ potassium ferricyanide and $1 \mathrm{M}$ potassium chloride solutions were placed in the electrochemical cell. Figure 1 shows the cyclic voltammograms recorded for the $1 \times 10^{-3} \mathrm{M}$ potassium ferricyanide at both BGPE (solid line) and at poly(XO)/GPE (dashed line) at scan rate of $50 \mathrm{mV} \mathrm{s}^{-1}$. The low redox current signals were observed at BGPE. The anodic and cathodic peak potentials were located at $171 \mathrm{mV}$ and $283 \mathrm{mV}$. The redox peak potentials difference $\left(\Delta E_{\mathrm{p}}\right)$ was $112 \mathrm{mV}$. But the poly $(\mathrm{XO}) / \mathrm{GPE}$ showed significant improvement in the redox peak current signals. The anodic and cathodic peak potentials were found at $169 \mathrm{mV}$ and 
$289 \mathrm{mV}$. The $\Delta E_{\mathrm{p}}$ was $120 \mathrm{mV}$. This shows the electrocatalytic property of poly $(\mathrm{XO}) / \mathrm{GPE}$.

3.2. Electrocatalytic Response of DA at Poly(XO)/GPE. Figure 2(a) explains the cyclic voltammogram of $0.5 \times 10^{-5} \mathrm{M}$ $\mathrm{DA}$ in $0.2 \mathrm{M}$ PBS at $\mathrm{pH} 7$ at BGPE and poly $(\mathrm{XO}) / \mathrm{GPE}$ at $50 \mathrm{mV} \mathrm{s}^{-1}$ sweep rate. The poor electrochemical response was observed at BGPE (solid line). The oxidation peak potential $\left(E_{\mathrm{pa}}\right)$ was located at $240 \mathrm{mV}$ and reduction peak potential $\left(E_{\mathrm{pc}}\right)$ response at $110 \mathrm{mV}$ were observed at BGPE. The potential difference $\left(\Delta E_{\mathrm{p}}\right)$ was found to be $130 \mathrm{mV}$. However the strong improvement and reversible redox peaks current were observed at poly $(\mathrm{XO}) / \mathrm{GPE}$. During the first cycle (dashed line) the $E_{\mathrm{pal}}$ and $E_{\mathrm{pcl}}$ were located at $200 \mathrm{mV}$ and $160 \mathrm{mV}$, respectively, and another reduction peak $E_{\mathrm{pc} 2}$ was found at $-250 \mathrm{mV}$. The $\Delta E_{\mathrm{p}}\left(E_{\mathrm{pal}}\right.$ and $\left.E_{\mathrm{pcl}}\right)$ was $40 \mathrm{mV}$. This is the clear evidence that our electrode has better electrocatalytic activity by exposing large surface area for electrochemical oxidation of DA. In the same condition, the poly $(\mathrm{XO}) / \mathrm{GPE}$ was scanned again. The resultant voltammogram (dotted line) shows another anodic peak $E_{\mathrm{pa} 2}$ at $-200 \mathrm{mV}$. The oxidation mechanism of DA at poly(XO)/GPE could be explained as shown in Scheme 2. During the first scan the DA was oxidized and converted to dopa- $O$-quinone $\left(E_{\mathrm{pal}}\right)$ in forward scan. While in reverse scan this was reduced to $\mathrm{DA}\left(E_{\mathrm{pc} 1}\right)$. The $E_{\mathrm{pc} 2}$ was appeared by next to the $E_{\mathrm{pcl}}$. This is because, the electron-rich nitrogen atom becomes deprotonated leads to formation of cyclized product known as lucodopachrome. By applying the second scan $E_{\mathrm{pa} 2}$ appeared because of the lucodopachrome oxidized to dopachrome $[9,26-30]$.

To understand whether the $E_{\mathrm{pc} 2}$ and $E_{\mathrm{pa} 2}$ were exist or not, the experiment was carried out at poly $(\mathrm{XO}) / \mathrm{GPE}$ by applying successive multiple cycle in the same above mentioned solution and condition. The voltammogram was recorded for 20 multiple cycles (Figure 2(b)). The voltammogram shows negligible decrease for second and third cycles and almost constant for further cycles and the results shows $E_{\mathrm{pc} 2}$ and $E_{\mathrm{pa} 2}$ were existing strongly. This confirms that DA was undergoing ring cyclization, that is, lucodopachrome and that was oxidizing to dopachrome.

3.3. Effect of Scan Rate towards the Electro-Oxidation of $D A$ at Poly $(X O) / G P E$. To study the scan rate effect at poly $(\mathrm{XO}) / \mathrm{GPE}$ the voltammograms were recorded for different scan rate. The cyclic voltammogram recorded for $0.5 \times 10^{-5} \mathrm{M}$ DA in $0.2 \mathrm{M}$ PBS at $\mathrm{pH} 7.4$ at different scan rates at poly $(\mathrm{XO}) / \mathrm{GPE}$, respectively. The redox peak currents were increased with increase in the scan rate from 50 to $400 \mathrm{mV} \mathrm{s}^{-1}$. The graph of redox peak current versus square root of scan rate was plotted (Figure 3 ). The graphs shows linear relations ships between redox peak currents and scan rates. The correlation coefficient occurred was $r^{2}=0.999$ suggested diffusion-controlled electrode process. Further the graph of $E_{p}$ versus $\ln v$ was plotted to calculate the heterogeneous rate constant and number of electron transferred in the electrochemical oxidation of DA. These parameters were calculated by using the equation given below $[31,32]$

$$
\begin{gathered}
E_{\mathrm{pa}}=E^{0}+m\left[0.78+\ln \left(\frac{D^{1 / 2}}{k^{0}}\right)-0.5 \ln m\right]+0.5 m \ln v \\
m=\frac{R T}{[(1-\alpha) n F]}, \\
E_{\mathrm{pc}}=E^{0}-m^{\prime}\left[0.78+\ln \left(\frac{D^{1 / 2}}{k^{0}}\right)-0.5 \ln m^{\prime}\right]-0.5 m \ln v \\
m^{\prime}=\frac{R T}{[\alpha n F]},
\end{gathered}
$$

where $E^{0}$ is the formal potential, $D$ is the diffusion coefficient, $k^{0}$ is the heterogeneous rate constant, $\alpha$ is the energy transferred coefficient and $n$ is the number of electrons transferred. $R, T$, and $F$ are the universal gas constant, absolute temperature and Faraday constant, respectively.

The $k^{0}$ was calculated from the above equation and it was found to be $0.0055 \mathrm{~cm} \mathrm{~s}^{-1}$ for forward electrochemical reaction and $0.0048 \mathrm{~cm} \mathrm{~s}^{-1}$ for backword electrochemical reaction at poly $(\mathrm{XO}) / \mathrm{GPE}$. The average $k^{0}$ was $0.00515 \mathrm{~cm} \mathrm{~s}^{-1}$. This calculated rate constant was higher when compared to the rate constant for BGPE $0.0005 \mathrm{~cm} \mathrm{~s}^{-1}$. The graph of $\ln$ Ip versus $\left(E \mathrm{p}-E^{0}\right)$ were plotted for the poly $(\mathrm{XO}) / \mathrm{GPE}$. The slope values from the above graph were used to calculate the energy transfer coefficient $(\alpha)$ using the equation $(5)[31,32]$

$$
I_{\mathrm{p}}=0.227 F A C_{0} k^{0} \exp \left[-\alpha f\left(E_{\mathrm{p}}-E^{0}\right)\right]
$$

where $A$ is the surface area of the electrode, $C_{0}$ is the concentration of DA and $f=F / R T$.

The calculated average energy transfer coefficients were 0.662 for BGPE and 0.635 for poly $(\mathrm{XO}) / \mathrm{GPE}$. From this energy transfer coefficients the number of electrons transferred in the electrochemical redox process for DA were calculated using (2) and (4).

In our case the number of electrons transferred were $n_{a}=$ 1.93 for anodic peak and $n_{c}=1.75$ for cathodic peak when working electrode used was poly $(\mathrm{XO}) / \mathrm{GPE}$. Hence from this evidence this was confirmed that the electrochemical redox process of DA at poly $(\mathrm{XO}) / \mathrm{GPE}$ was carried by transferring the two electrons.

3.4. Effect of Solution $p H$. The electrochemical response of $\mathrm{DA}$ at poly $(\mathrm{XO}) / \mathrm{GPE}$ was generally $\mathrm{pH}$ dependent. The both redox peak potentials of DA were shifted to less positive side with increasing in the $\mathrm{pH}$ values. The anodic peak potential of DA shifted from $300 \mathrm{mV}$ to $90 \mathrm{mV}$ with respect the $\mathrm{pH}$ from 4 to 10 . The potential diagram was constructed by plotting the graph of $E_{\mathrm{pal}}$ versus $\mathrm{pH}$ of the solution (Figure 4). The graph has good linearity with a slope of $54 \mathrm{mV} / \mathrm{pH}$ suggested, equal number of electron and proton transfer reactions [33-35]. 


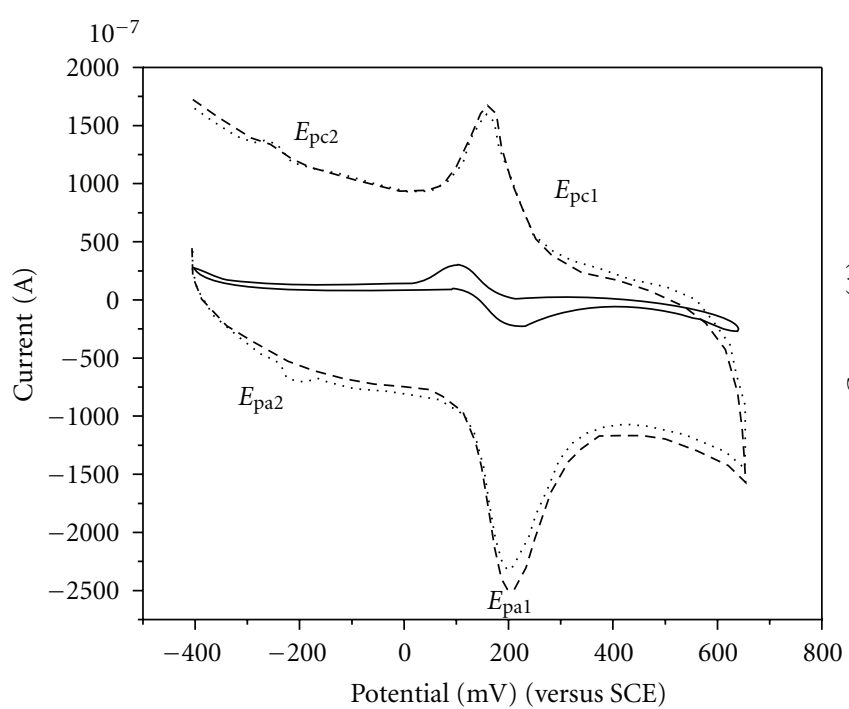

(a)

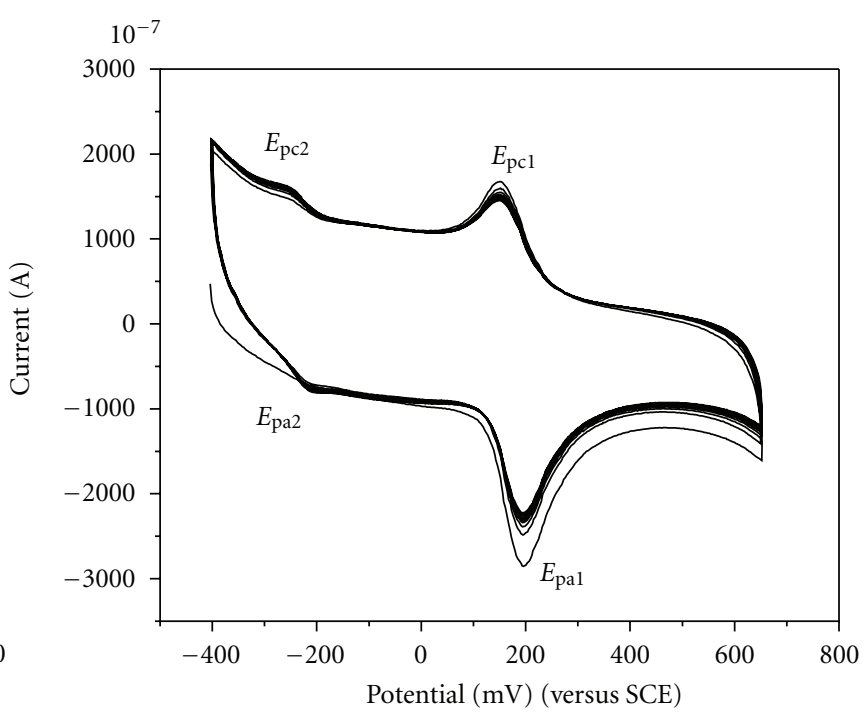

(b)

Figure 2: (a) Cyclic voltammograms of $0.5 \times 10^{-5} \mathrm{M}$ dopamine at BGPE (solid line) and at poly(XO)/GPE; First cycle (dashed line) and Second Cycle (dotted line) in $0.2 \mathrm{M}$ PBS of $\mathrm{pH} 7$ at sweep rate $50 \mathrm{mV} \mathrm{s}^{-1}$. (b) Cyclic voltammograms of $0.5 \times 10^{-5} \mathrm{M}$ dopamine for 20 multiple cycles in $0.2 \mathrm{M}$ PBS at poly(XO)/GPE at sweep rate $50 \mathrm{mV} \mathrm{s}^{-1}$.<smiles></smiles><smiles>[NH3+]CCC1=CC(=O)C(=O)C=C1</smiles>

Dopamine-o-quinone<smiles>Oc1cc2c(cc1O)NCC2</smiles>

Lucodopachrome<smiles>[C-]#[P+][18F]</smiles>

Dopamine-o-quinone<smiles>Oc1cc2c(cc1O)NCC2</smiles>

Lucodopachrome

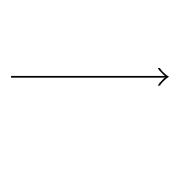

$\overbrace{\mathrm{O}}^{\mathrm{O}}$

Dopachrome

Scheme 2: Electrocatalytic oxidation mechanism of DA at the poly $(\mathrm{XO})$ GPE surface.

3.5. Simultaneous Determination of $D A, A A$, and UA. Further our poly $(\mathrm{XO}) / \mathrm{GPE}$ was introduced for analysis of $\mathrm{DA}$ in the mixture containing large excess of AA and UA. As shown in Figure 5(a), the cyclic voltammogram at BGPE (solid line) appear the seriously overlapped peak at around $240 \mathrm{mV}$ was observed for the mixture containing $0.5 \times 10^{-5} \mathrm{M} \mathrm{DA}$, $1 \times 10^{-4} \mathrm{M} \mathrm{AA}$, and $5 \times 10^{-5} \mathrm{M}$ UA in $0.2 \mathrm{M}$ PBS at $\mathrm{pH}$
7. However, resolved voltammetric peaks were obtained at poly $(\mathrm{XO}) / \mathrm{GPE}$ (dashed line) with great enhancement in current signals. The anodic peak potentials $\left(E_{\mathrm{pa} 1}\right.$ and $\left.E_{\mathrm{pa} 2}\right)$ of DA were found at 205 and $-205 \mathrm{mV}$. The corresponding $E_{\mathrm{pc} 1}$ and $E_{\mathrm{pc} 2}$ were located at 160 and -250 , respectively. The anodic peak potentials of AA and UA were found at $10 \mathrm{mV}$ and $350 \mathrm{mV}$, respectively. The difference of anodic 
TABLE 1: Comparison of different modified electrodes for DA determination.

\begin{tabular}{lccc}
\hline Electrode & Detection limit $(\mu \mathrm{mol} / \mathrm{L})$ & Method & Reference \\
\hline Triazole Self-Assembled Monolayer-Modified Gold Electrode & 0.5 & DPV & {$[36]$} \\
Metallothioneins self-assembled gold electrode & 6 & $\mathrm{CV}$ & $\mathrm{CV}$ \\
IL-CPE & 0.7 & $\mathrm{CV}$ & {$[37]$} \\
Poly(L-methionine) Modified Electrode & 0.42 & DPV & {$[31]$} \\
P-pTSA modified electrode & 0.6 & DPV & {$[39]$} \\
poly $(\mathrm{XO}) /$ GPE & 0.091 & This work
\end{tabular}

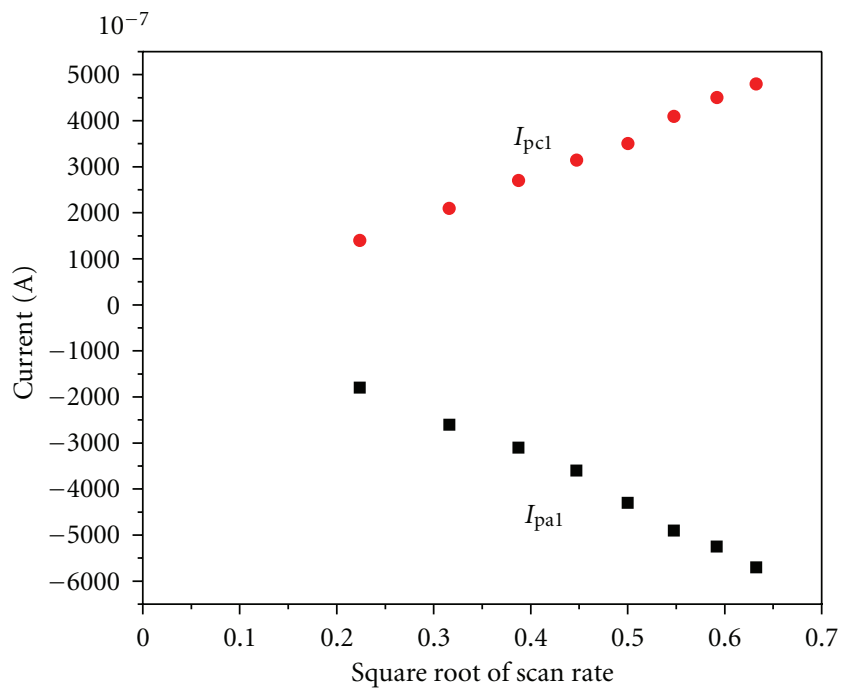

FIGURE 3: Graph of redox peak current of DA versus different scan rate.

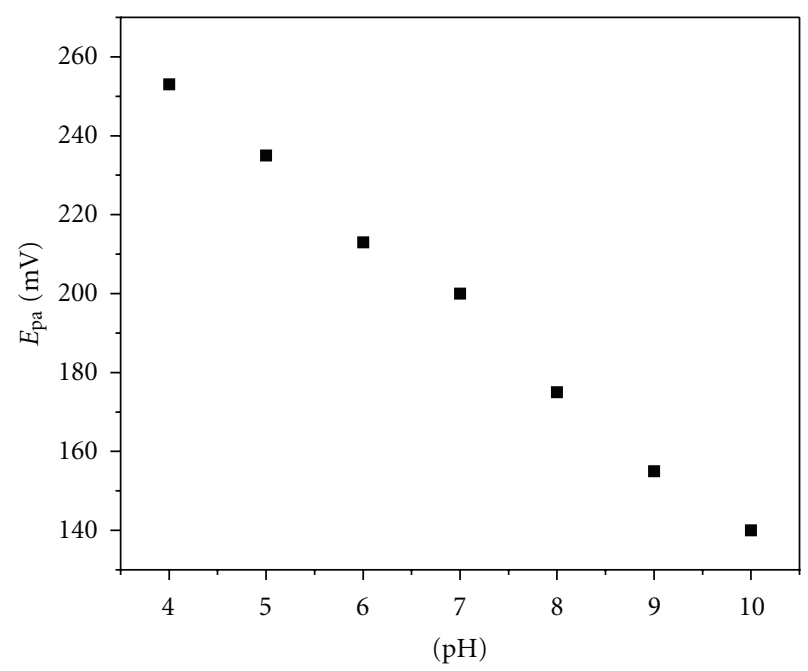

FIGURE 4: Graph of anodic peak potential $\left(E_{\mathrm{pal}}\right)$ of DA versus different $\mathrm{pH}$.

peak potential between DA $\left(E_{\mathrm{pal}}\right)$-AA was $195 \mathrm{mV}$ and to that of UA-DA $\left(E_{\mathrm{pal}}\right)$ was $145 \mathrm{mV}$ by CV technique.

DPV technique was used for the determination of DA, $\mathrm{AA}$, and UA at both BGPE and poly (XO)/GPE because to get higher current sensitivity and better resolution. Figure 5(b) shows the DPVs recorded for the mixture of the same samples and condition mentioned above. The DPV recorded at BGPE shows a single and broad peak (solid line) and well-separated three anodic peaks of DA, AA, and UA were occurred at poly $(\mathrm{XO}) / \mathrm{GPE}$. The oxidation peaks of DA, $\mathrm{AA}$, and UA were located at $190 \mathrm{mV},-20 \mathrm{mV}$ and $360 \mathrm{mV}$, respectively. The anodic peak potential differences between DA-AA and UA-DA were $210 \mathrm{mV}$ and $170 \mathrm{mV}$, respectively. The peak separation were greater when comparing to peak separation occurred by $\mathrm{CV}$.

3.6. Calibration of DA Concentration. The incorporation study of DA was carried out in its mixture at poly (XO)/GPE when the concentration of DA was increased whereas the concentration of AA and UA were keep constant. From Figure 6(a), it can be seen that the concentration of DA was increased from $0.2 \times 10^{-5} \mathrm{M}$ to $0.9 \times 10^{-5} \mathrm{M}$ when keeping the concentration of UA $5 \times 10^{-5} \mathrm{M}$ and AA $1 \times 10^{-4} \mathrm{M}$. The anodic peak current was proportional to concentration of DA and there were no change in the peak current and peak potential occurred for AA and UA. The graph of anodic peak current of DA was plotted against its concentration (Figure 6(b)). The correlation coefficient was found to be 0.9989. The linear regression equation was $I_{\mathrm{pa}}(\mu A)=$ $47.416(\mu \mathrm{M} / \mathrm{L})+23.833$. The limit of detection and limit of quantification were calculated by using the equations given below (6) and (7), respectively, $[18,40]$. The limit of detection and quantification were $9.1 \times 10^{-8} \mathrm{M}$ and $3.03 \times$ $10^{-7} \mathrm{M}$, respectively, and this was compared with the other literatures [36-39, 41] (Table 1)

$$
\begin{aligned}
\text { LOD } & =3 \frac{S}{M}, \\
\text { LOQ } & =10 \frac{S}{M},
\end{aligned}
$$

where $S$ is standard deviation and $M$ is the slope of calibration plot.

3.7. Analytical Application. The modified electrode was applied to the determination of dopamine hydrochloride injection. The DA injection sample purchased from Sterile Specialities India Private Ltd with a specified content of DA of $40.0 \mathrm{mg} / \mathrm{mL}$. The sample was used after suitable dilution using 0.2 M PBS. The recovery and R.S.D. were acceptable ( $n=5)$, showing that the proposed methods could be efficiently used for the determination of DA in injections with recovery in the range $98.5-100.05 \%$ (Table 2 ). 


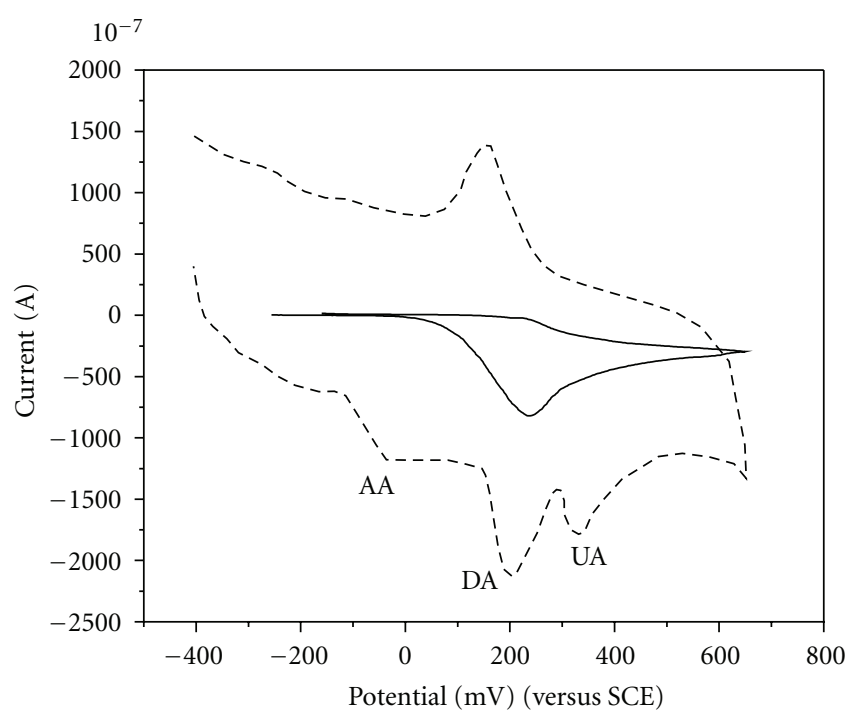

(a)

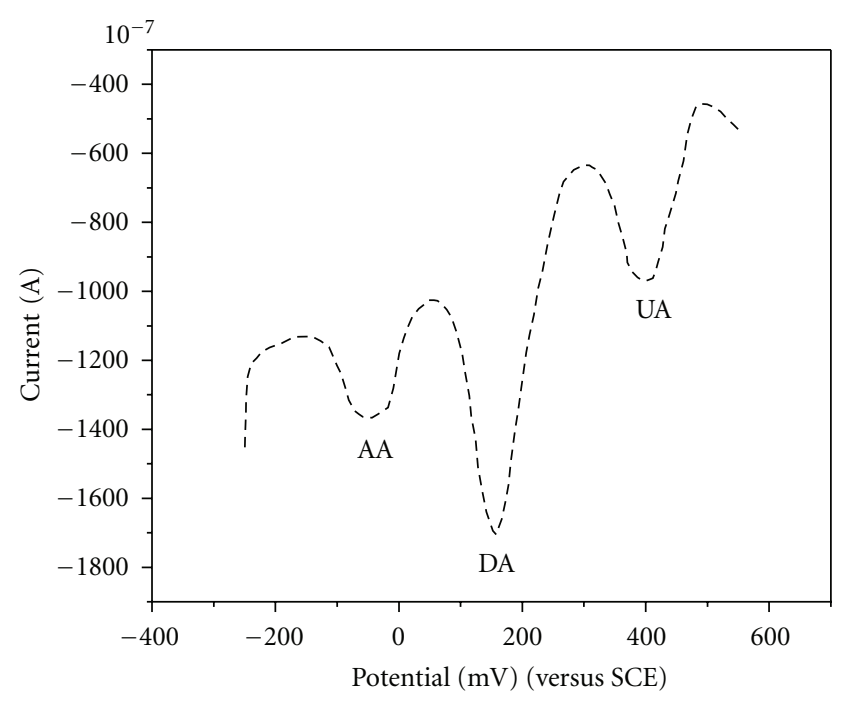

(b)

FIGURE 5: (a) Simultaneous detection of $0.5 \times 10^{-5} \mathrm{M} \mathrm{DA}, 1 \times 10^{-4} \mathrm{M}$ AA, and $5 \times 10^{-5} \mathrm{M}$ UA at BGPE (solid line) and at poly(XO)/GPE (dashed line) by CV at scan rate of $50 \mathrm{mV} \mathrm{s}^{-1}$. (b) Simultaneous detection of $0.5 \times 10^{-5} \mathrm{M} \mathrm{DA}, 1 \times 10^{-4} \mathrm{M} \mathrm{AA}$, and $5 \times 10^{-5} \mathrm{M} \mathrm{UA}$ at BGPE (solid line) and at poly $(\mathrm{XO}) / \mathrm{GPE}$ (dashed line) by DPV at scan rate of $20 \mathrm{mV} \mathrm{s}^{-1}$.

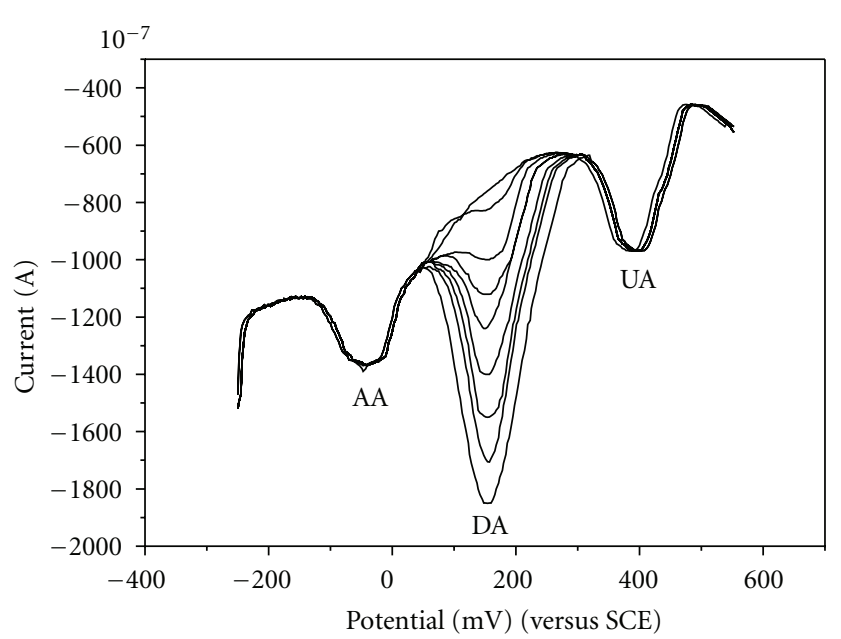

(a)

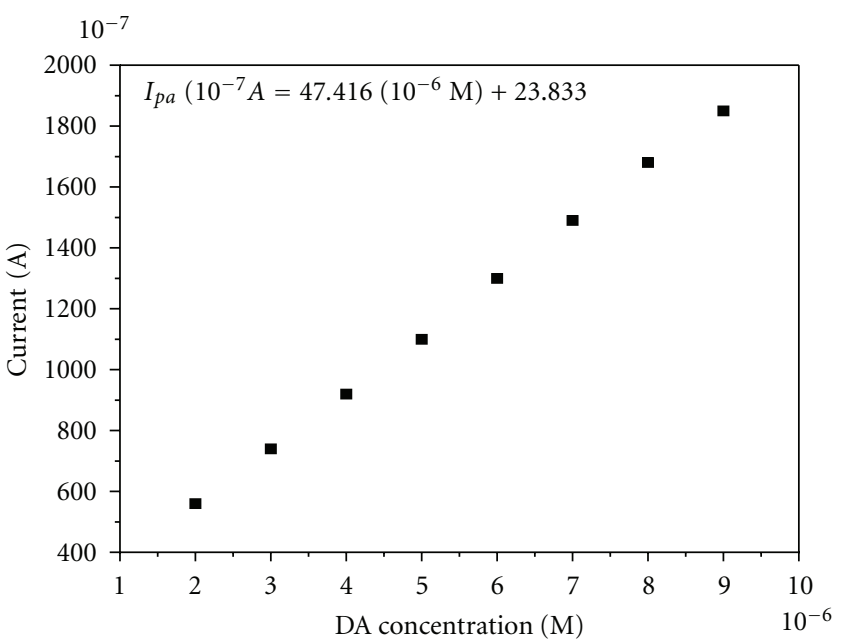

(b)

Figure 6: (a) Differential pulse voltammograms of different concentrationof DA (a-g; 0.2, 0.3, 0.4, 0.5, 0.5, 0.6, $0.7,0.8$ and $0.9 \times 10^{-5} \mathrm{M}$ in $0.2 \mathrm{M}$ phosphate buffer solution of $\mathrm{pH} 7.0$ in the presence of $1 \times 10^{-3} \mathrm{M} \mathrm{AA}$, and $5 \times 10^{-4} \mathrm{M}$ UA at poly(XO)/GPE. (b) Graph of anodic peak current versus different concentration of DA.

TABLE 2: Detection of DA in injection samples $(n=5)$.

\begin{tabular}{lcccc}
\hline Sample & $\begin{array}{c}\text { Content } \\
(\mathrm{mg} / \mathrm{mL})\end{array}$ & $\begin{array}{c}\text { Found } \\
(\mathrm{mg} / \mathrm{mL})\end{array}$ & $\begin{array}{c}\text { RSD } \\
(\%)\end{array}$ & $\begin{array}{c}\text { Recovery } \\
(\%)\end{array}$ \\
\hline 1 & 4.0 & 3.94 & 2.4 & 98.5 \\
2 & 4.0 & 3.968 & 2.0 & 99.2 \\
3 & 4.0 & 4.002 & 2.2 & 100.05 \\
\hline
\end{tabular}

\section{Conclusion}

DA can be detected electrochemically in mixture of solution, at physiological $\mathrm{pH}$, containing large excess of $\mathrm{AA}$ and $\mathrm{UA}$ at poly $(\mathrm{XO}) / \mathrm{GPE}$. The prepared modified electrode detection limit was $9.1 \times 10^{-8} \mathrm{M}$ and it has excellent sensitivity, selectivity and antifouling properties. The proposed methods can be applied to the detection of DA in injection. This approach can readily be applied to the development of electrochemical sensors for dopamine and related neurotransmitters.

\section{Acknowledgment}

The authors are very thankful to the Department of Science and Technology, Government of India, New Delhi for the funding given through project no. DST/TSG/ME/2007/44. 


\section{References}

[1] W. Gao, J. Song, and N. Wu, "Voltammetric behavior and square-wave voltammetric determination of trepibutone at a pencil graphite electrode," Journal of Electroanalytical Chemistry, vol. 576, no. 1, pp. 1-7, 2005.

[2] D. Demetriades, A. Economou, and A. Voulgaropoulos, "A study of pencil-lead bismuth-film electrodes for the determination of trace metals by anodic stripping voltammetry," Analytica Chimica Acta, vol. 519, no. 2, pp. 167-172, 2004.

[3] H. Karadeniz, B. Gulmez, F. Sahinci et al., "Disposable electrochemical biosensor for the detection of the interaction between DNA and lycorine based on guanine and adenine signals," Journal of Pharmaceutical and Biomedical Analysis, vol. 33, no. 2, pp. 295-302, 2003.

[4] A. Levent, Y. Yardim, and Z. Senturk, "Voltammetric behavior of nicotine at pencil graphite electrode and its enhancement determination in the presence of anionic surfactant," Electrochimica Acta, vol. 55, no. 1, pp. 190-195, 2009.

[5] M. Vestergaard, K. Kerman, and E. Tamiya, "An electrochemical approach for detecting copper-chelating properties of flavonoids using disposable pencil graphite electrodes: possible implications in copper-mediated illnesses," Analytica Chimica Acta, vol. 538, no. 1-2, pp. 273-281, 2005.

[6] A. Erdem, P. Papakonstantinou, and H. Murphy, "Direct DNA hybridization at disposable graphite electrodes modified with carbon nanotubes," Analytical Chemistry, vol. 78, no. 18, pp. 6656-6659, 2006.

[7] M. Ozsoz, A. Erdem, K. Kerman et al., "Electrochemical genosensor based on colloidal gold nanoparticles for the detection of factor $\mathrm{V}$ leiden mutation using disposable pencil graphite electrodes," Analytical Chemistry, vol. 75, no. 9, pp. 2181-2187, 2003.

[8] J. Wang, A. N. Kawde, and E. Sahlin, "Renewable pencil electrodes for highly sensitive stripping potentiometric measurements of DNA and RNA," Analyst, vol. 125, no. 1, pp. 5-7, 2000.

[9] U. Chandra, B. E. Kumara Swamy, O. Gilbert et al., "Poly (amaranth) film based sensor for resolution of dopamine in the presence of uric acid: a voltammetric study," Chinese Chemical Letters, vol. 21, no. 12, pp. 1490-1492, 2010.

[10] O. Gilbert, U. Chandra, B. E. K. Swamy, M. PandurangaChar, C. Nagaraj, and B. S. Sherigara, "Poly (alanine) modified carbon paste electrode for simultaneous detection of dopamine and ascorbic acid," International Journal of Electrochemcal Science, vol. 3, pp. 1186-1195, 2008.

[11] M. Pandurangachar, B. E. K. Swamy, U. Chandra, and B. S. Sherigara, "Simultaneous determination of dopamine, ascorbic acid and uric acid at poly(patton and reeder's) modified carbon paste electrode," International Journal of Electrochemical Science, vol. 4, no. 5, pp. 672-683, 2009.

[12] O. Gilbert, B. E. K. Swamy, U. Chandra, and B. S. Sherigara, "Electrocatalytic oxidation of dopamine and ascorbic acid at poly (eriochrome black-T) modified carbon paste electrode," International Journal of Electrochemical Science, vol. 4, no. 4, pp. 582-591, 2009.

[13] Y. Ohnuki, H. Matsuda, T. Ohsaka, and N. Oyama, "Permselectivity of films prepared by electrochemical oxidation of phenol and amino-aromatic compounds," Journal of Electroanalytical Chemistry, vol. 158, no. 1, pp. 55-67, 1983.
[14] A. Volkov, G. Tourillon, P. C. Lacaze, and J. E. Dubois, "Electrochemical polymerization of aromatic amines. IR, XPS and PMT study of thin film formation on a Pt electrode," Journal of Electroanalytical Chemistry, vol. 115, no. 2, pp. 279291, 1980 .

[15] C. X. Cai and K. H. Xue, "Electrochemical characterization of electropolymerized film of naphthol green B and its electrocatalytic activity toward NADH oxidation," Microchemical Journal, vol. 58, no. 2, pp. 197-208, 1998.

[16] A. A. Karyakin, O. A. Bobrova, and E. E. Karyakina, "Electroreduction of $\mathrm{NAD}^{+}$to enzymatically active $\mathrm{NADH}$ at poly(neutral red) modified electrodes," Journal of Electroanalytical Chemistry, vol. 399, no. 1-2, pp. 179-184, 1995.

[17] A. A. Karyakin, A. K. Strakhova, E. E. Karyakina, S. D. Verfolomeyev, and A. K. Yatsimirsky, "The electrochemical polymerization of methylene blue and bioelectrochemical activity of the resulting film," Bioelectrochemistry and Bioenergetics, vol. 32, no. 1, pp. 35-43, 1993.

[18] U. Chandra, B. E. Kumara Swamy, O. Gilbert, and B. S. Sherigara, "Voltammetric resolution of dopamine in the presence of ascorbic acid and uric acid at poly (calmagite) film coated carbon paste electrode," Electrochimica Acta, vol. 55, no. 24, pp. 7166-7174, 2010.

[19] O. Gilbert, B. E. Kumara Swamy, U. Chandra, and B. S. Sherigara, "Simultaneous detection of dopamine and ascorbic acid using polyglycine modified carbon paste electrode: a cyclic voltammetric study," Journal of Electroanalytical Chemistry, vol. 636, no. 1-2, pp. 80-85, 2009.

[20] U. Chandra, B. E. Kumara Swamy, O. Gilbert, M. Pandurangachar, and B. S. Sherigara, "Voltammetric resolution of dopamine in presence of ascorbic acid at polyvinyl alcohol modified carbon paste electrode," International Journal of Electrochemical Science, vol. 4, no. 10, pp. 1479-1488, 2009.

[21] U. Chandra, B. E. Kumara Swamy, O. Gilbert, and B. S. Sherigara, "Determination of dopamine in presence of ascorbic acid at eriochrome black T modified carbon paste electrode: a voltammetric study," International Journal of Electrochemical Science, vol. 5, no. 10, pp. 1475-1483, 2010.

[22] R. N. Adams, "Probing brain chemistry with electroanalytical techniques," Analytical Chemistry, vol. 48, no. 14, pp. 1126A1138A, 1976.

[23] R. R. Naik, B. E. K. Swamy, U. Chandra, E. Niranjana, B. S. Sherigara, and H. Jayadevappa, "Separation of ascorbic acid, dopamine and uric acid by acetone/water modified carbon paste electrode: a cyclic voltammetric study," International Journal of Electrochemical Science, vol. 4, no. 6, pp. 855-862, 2009.

[24] G. Alarcón-Angeles, S. Corona-Avendaño, M. PalomarPardavé, A. Rojas-Hernández, M. Romero-Romo, and M. T. Ramírez-Silva, "Selective electrochemical determination of dopamine in the presence of ascorbic acid using sodium dodecyl sulfate micelles as masking agent," Electrochimica Acta, vol. 53, no. 6, pp. 3013-3020, 2008.

[25] S. Corona-Avendaño, G. Alarcón-Ángeles, M. T. RamírezSilva, M. Romero-Romo, A. Cuán, and M. Palomar-Pardavé, "Simultaneous electrochemical determination of adrenaline and ascorbic acid: influence of [CTAB]," Journal of the Electrochemical Society, vol. 156, no. 12, pp. J375-J381, 2009.

[26] Y. Zhang, G. Jin, Y. Wang, and Z. Yang, "Determination of dopamine in the presence of ascorbic acid using poly 
(acridine red) modified glassy carbon electrode," Sensors, vol. 3, no. 10, pp. 443-450, 2003.

[27] E. S. Forzani, G. A. Rivas, and V. M. Solís, "Amperometric determination of dopamine on vegetal-tissue enzymatic electrodes. Analysis of interferents and enzymatic selectivity," Journal of Electroanalytical Chemistry, vol. 435, no. 1-2, pp. 77-84, 1997.

[28] A. Ciszewski and G. Milczarek, "Polyeugenol-modified platinum electrode for selective detection of dopamine in the presence of ascorbic acid," Analytical Chemistry, vol. 71, no. 5, pp. 1055-1061, 1999.

[29] Y. Zhang, G. Jin, Z. Yang, and H. Zhao, "Determination of dopamine in the presence of ascorbic acid using a poly(amidosulfonic acid) modified glassy carbon electrode," Microchimica Acta, vol. 147, no. 4, pp. 225-230, 2004.

[30] Y. Zhang, G. Jin, W. Cheng, and S. Li, "Poly (O-aminobenzoic acid) modified glassy carbon electrode for electrochemical detection of dopamine in the presence of ascorbic acid," Frontiers in Bioscience, vol. 10, no. 1, pp. 23-29, 2005.

[31] S. Corona-Avendaño, M. T. Ramírez-Silva, M. PalomarPardavé, L. Hernández-Martínez, M. Romero-Romo, and G. Alarcón-Ángeles, "Influence of CTAB on the electrochemical behavior of dopamine and on its analytic determination in the presence of ascorbic acid," Journal of Applied Electrochemistry, vol. 40, no. 2, pp. 463-474, 2010.

[32] S. Corona-Avendaño, G. Alarcón-Angeles, M. T. RamírezSilva, G. Rosquete-Pina, M. Romero-Romo, and M. PalomarPardavé, "On the electrochemistry of dopamine in aqueous solution. Part I: the role of [SDS] on the voltammetric behavior of dopamine on a carbon paste electrode," Journal of Electroanalytical Chemistry, vol. 609, no. 1, pp. 17-26, 2007.

[33] B. D. Jones and J. D. Ingle Jr., "Evaluation of immobilized redox indicators as reversible, in situ redox sensors for determining $\mathrm{Fe}(\mathrm{III})$-reducing conditions in environmental samples," Talanta, vol. 55, no. 4, pp. 699-714, 2001.

[34] S. M. Chen, G. H. Chuang, and V. S. Vasantha, "Preparation and electrocatalytic properties of the $\mathrm{TBO} /$ nafion chemicallymodified electrodes," Journal of Electroanalytical Chemistry, vol. 588, no. 2, pp. 235-243, 2006.

[35] X. Wang, N. Yang, Q. Wan, and X. Wang, "Catalytic capability of poly(malachite green) films based electrochemical sensor for oxidation of dopamine," Sensors and Actuators, B, vol. 128, no. 1, pp. 83-90, 2007.

[36] S. Yixin and S. F. Wang, "Simultaneous determination of dopamine and ascorbic acid at a triazole self-assembled monolayer-modified gold electrode," Microchimica Acta, vol. 154, no. 1-2, pp. 115-121, 2006.

[37] Q. Wang, N. Li, and W. Wang, "Electrocatalytic response of dopamine at a metallothioneins self-assembled gold electrode," Analytical Sciences, vol. 18, no. 6, pp. 635-639, 2002.

[38] W. Ma and D. M. Sun, "The electrochemical properties of dopamine, epinephrine and their simultaneous determination at a poly(L-methionine) modified electrode," Russian Journal of Electrochemistry, vol. 43, no. 12, pp. 1382-1389, 2007.

[39] P. F. Huang, L. Wang, J. Y. Bai, H. J. Wang, Y. Q. Zhao, and S. D. Fan, "Simultaneous electrochemical detection of dopamine and ascorbic acid at a poly ( $p$-toluene sulfonic acid) modified electrode," Microchimica Acta, vol. 157, no. 1-2, pp. 41-47, 2007.

[40] R. N. Hegde, B. E. Kumara Swamy, N. P. Shetti, and S. T. Nandibewoor, "Electro-oxidation and determination of gabapentin at gold electrode," Journal of Electroanalytical Chemistry, vol. 635, no. 1, pp. 51-57, 2009.
[41] W. Sun, M. Yang, and K. Jiao, "Electrocatalytic oxidation of dopamine at an ionic liquid modified carbon paste electrode" and its analytical application," Analytical and Bioanalytical Chemistry, vol. 389, no. 4, pp. 1283-1291, 2007. 


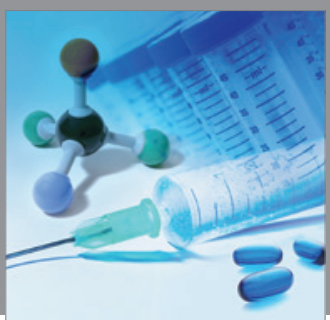

International Journal of

Medicinal Chemistry

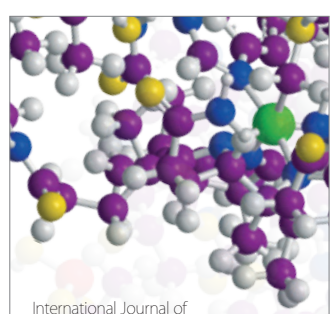

Carbohydrate Chemistry

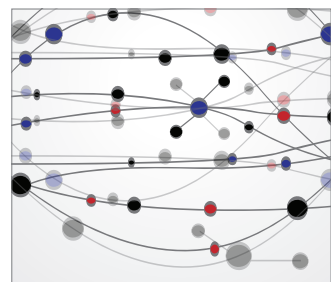

The Scientific World Journal
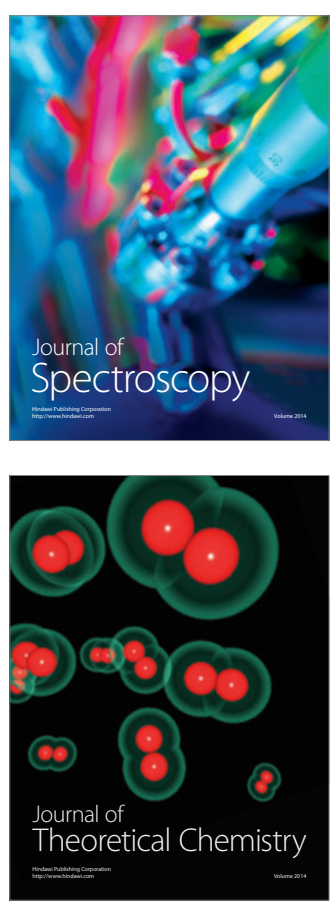
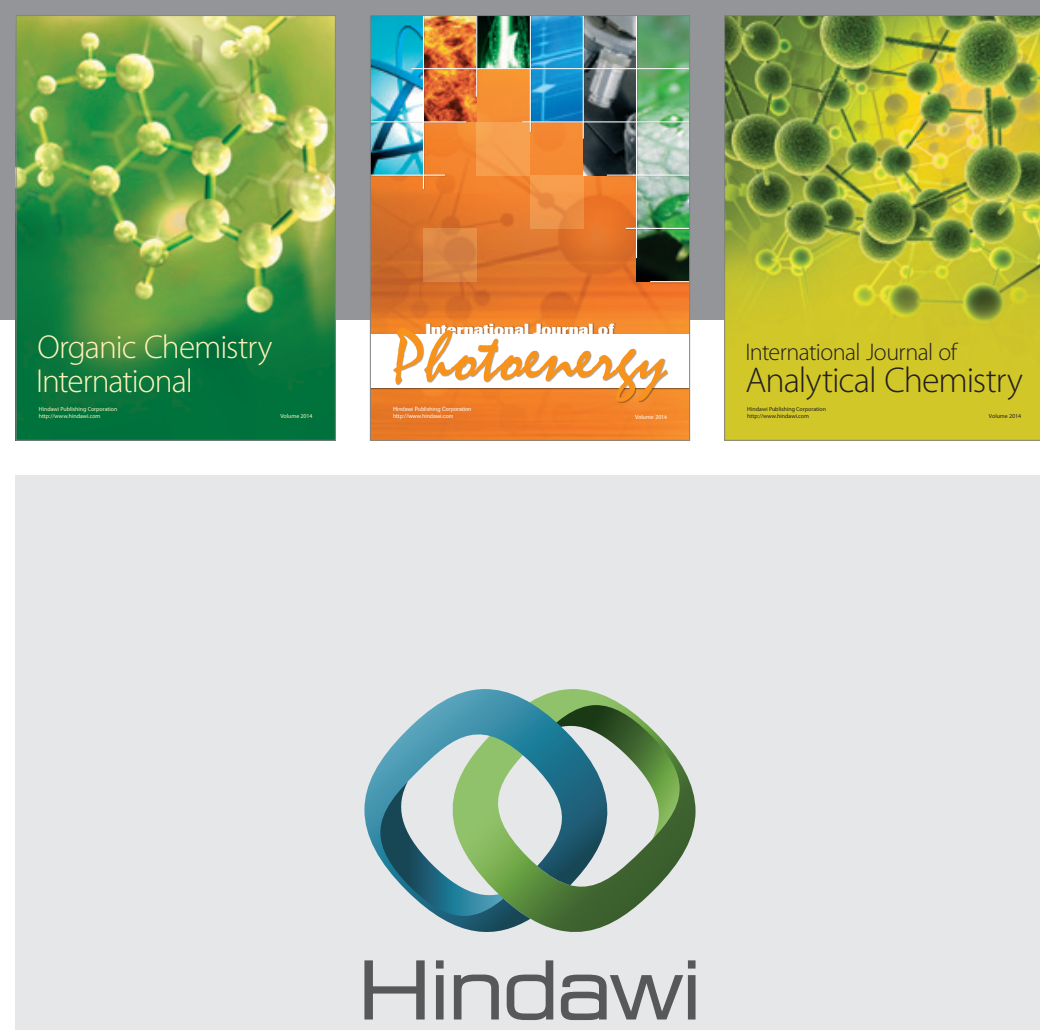

Submit your manuscripts at

http://www.hindawi.com
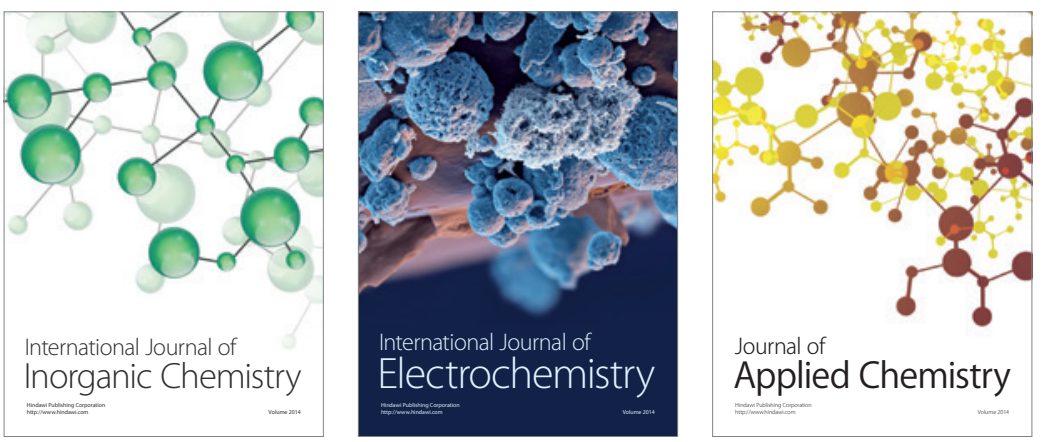

Journal of

Applied Chemistry
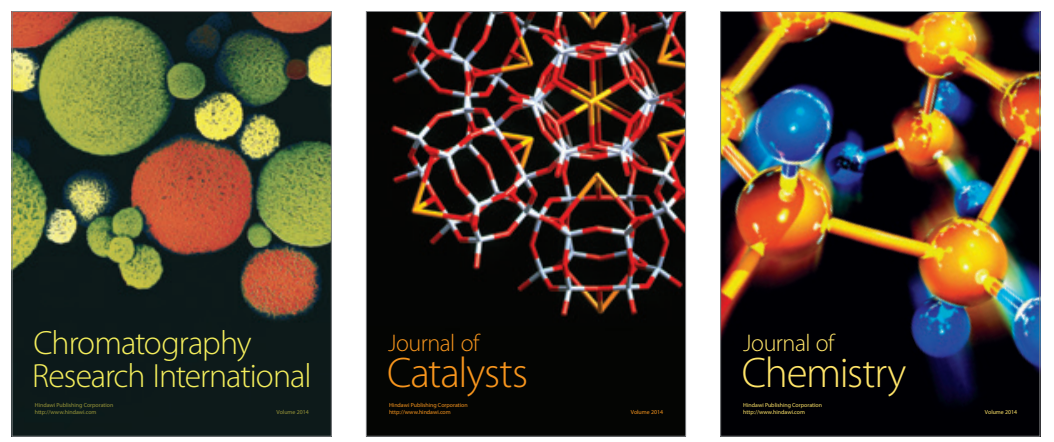
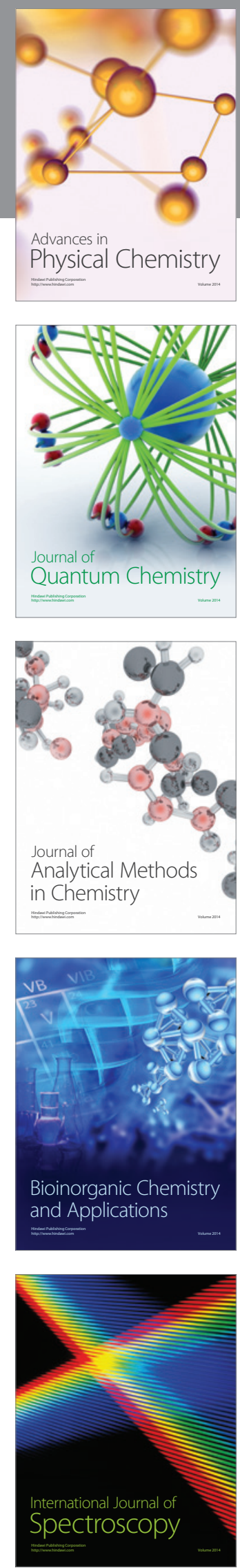